\title{
Capitalismo, cuestión agraria y trabajo asalariado: una relectura de los debates clásicos a partir de datos de la pampa húmeda argentina y el corn belt estadounidense $^{\mathrm{l}}$
}

\author{
Juan Manuel Villulla ${ }^{2}$
}

\section{Resumen}

Este artículo aborda la relación entre la cuestión agraria y el desarrollo capitalista, a partir de un análisis crítico del lugar que se la ha dado en el marxismo europeo de principios del siglo XX al trabajo asalariado en el marco de esta problemática y de una comparación internacional de las formas contemporáneas de asalarización del trabajo (absoluta y relativa) en los sectores agropecuarios de la Pampa Húmeda argentina y el medio oeste de los Estados Unidos. Nuestra hipótesis es que, si bien el predominio productivo del trabajo asalariado contribuye a caracterizar una estructura social agraria como capitalista, reducir a esa variable los análisis expresa un enfoque limitado teóricamente y restricto a las circunstancias de las transiciones al capitalismo en Europa hace más de cien años. En la actualidad, el mismo fenómeno puede darse por igual en distintos tipos de capitalismo, y, por lo tanto, dar lugar a distintos tipos de «cuestiones agrarias» en diversas latitudes, no necesariamente asimilables a los esquemas lineales de aquellas primeras elaboraciones del problema.

\begin{abstract}
This article deals with the relationship between the agrarian question and capitalist development, based on a critical analysis of the place given in European Marxism at the beginning of the twentieth century to wage labour within the framework of this problem and on an international comparison of contemporary forms of asalarization of labour (absolute and relative) in the agricultural sectors of the Argentinean Humid Pampas and the Midwest of the United States. Our hypothesis is that, although the productive predominance of wage labor contributes to characterizing an agrarian social structure as capitalist, reducing to that variable the analyses expresses a theoretically limited and restricted approach to the circumstances of the transitions to capitalism in Europe more than one hundred years ago. At present, the same phenomenon can occur equally in different types of capitalism, and, therefore, give rise to different types of «agrarian questions» in different latitudes, not necessarily assimilable to the linear schemes of those first elaborations of the problem.
\end{abstract}

1 Trabajo recibido el 31/10/2018. Aceptado el 12/12/2018.

${ }^{2}$ Universidad de Buenos Aires. Consejo Nacional de Investigaciones Científicas y Técnicas. Contacto: jmvillulla@gmail.com 
Palabras clave: cuestión agraria - capitalismo - trabajo asalariado - Argentina - Estados Unidos
Keywords: agrarian question - capitalism hired labor - Argentina - United States

\section{Introducción}

Este artículo se propone repensar teóricamente la relación entre cuestión agraria, desarrollo capitalista y trabajo asalariado. Lo hacemos, en primer lugar, a partir de un análisis crítico del lugar que los marxistas europeos de principios del siglo XX le daban al trabajo asalariado agrario en el marco de ese debate; y, en segundo lugar, contrastando aquellas visiones con las formas de asalarización del trabajo en los sectores agropecuarios de la Pampa Húmeda argentina y del Corn Belt de los Estados Unidos en la actualidad. La primera parte del trabajo se basó en un intento de síntesis crítica y de reproblematización de la cuestión agraria a partir del análisis de una recopilación de textos y autores que, aunque no fuese exhaustiva, permitiera distinguir las posiciones básicas al respecto entre los marxistas que, precisamente, inventaron «la cuestión agraria». La segunda parte, dividida en dos secciones, se basó en el análisis comparativo de fuentes estadísticas de Argentina y Estados Unidos referidas al trabajo asalariado en sus sectores agropecuarios en la primera década del siglo XXI. A modo de muestra crítica (Patton, 2002), tomamos al estado de Iowa, en Estados Unidos, como representación estadística del Corn Belt, y a la provincia de Buenos Aires, en Argentina, como representación de la Pampa Húmeda, ya que son los principales distritos productores de los bienes característicos de sus regiones, condensan las tendencias sociales generales de sus respectivas zonas y, además, existe cierta tradición en la historiografía, la economía y la sociología de ambos países que ya ha intentado antes compararlos para debatir tipos distintos de desarrollo agrario. ${ }^{3}$

\footnotetext{
${ }^{3}$ Entre otros aportes, es posible mencionar los de Taylor (1949), Flichman (1978), Azcuy Ameghino (1997 y 2010), Balsa (2003 y 2009) o Volkind (2015). La particularidad de la presente comparación frente a las mencionadas es la de tomar como eje específicamente al trabajo asalariado y evaluar su significado en el marco de los problemas teóricos vinculados a la cuestión agraria. Por eso, si bien tomamos los trabajos mencionados como referencia, optamos por no reabrir aquellos debates que consideramos suficientemente abordados por dichos aportes, concentrándonos en este otro eje, menos tratado por los trabajos anteriores.
} 
Planteamos que, si bien tal como quedó planteado por los marxistas clásicos, el predominio productivo del trabajo asalariado caracteriza a una estructura social agraria como capitalista, ello no alcanza para identificar el tipo de capitalismo de que se trata, y, por lo tanto, tampoco el tipo de cuestión agraria específica ni los sujetos agrarios concretos de un territorio determinado en un momento dado. En efecto, lo que comprobamos a partir del análisis de los datos, es que la asalarización del trabajo puede darse por igual en distintos tipos de capitalismo, como el de Argentina y los Estados Unidos, en el marco de distintos tipos de cuestiones agrarias, no necesariamente asimilables a los esquemas lineales de las primeras elaboraciones del problema en la Europa de fines del siglo XIX y principios del XX. Ello invita a repensar la cuestión agraria argentina contemporánea a partir de un empleo crítico de aquellas categorías fundamentales de análisis, a la vez que abriendo espacio a nuevas teorizaciones -como las desarrolladas por algunos marxistas latinoamericanos contemporáneos- que den cuenta de las originalidades que distinguen nuestras latitudes y nuestro tiempo en América del Sur.

\section{Origen político del debate sobre la cuestión agraria y el trabajo asa- lariado}

La «cuestión agraria» como tal fue planteada inicialmente como un problema político-práctico de las organizaciones socialistas europeas a fines del siglo XIX. ${ }^{4}$ Esta «cuestión» se emparentaba a cómo integrar a

\footnotetext{
${ }^{4}$ Por el lado alemán, en palabras de Kautsky (2002 [1899]) «la defensa de los asalariados agrícolas no requeriría ningún programa particular: el actual de la socialdemocracia lo incluye. Pero si lo que se quiere es que la socialdemocracia asuma la representación del pequeño propietario rural, se hará necesario entonces un programa agrario especial» (p. 367). Por eso, atendiendo al problema de las mayorías sociales reales del agro alemán -obreras, pero también en gran medida aún campesinas-: «lo que más nos ocupa hoy día es precisamente el papel, dentro de la sociedad capitalista, de las formas pre-capitalistas y no capitalistas de la agricultura» (p. 367). En simultáneo, Lenin (1964 [1902]) planteaba que «hoy en día en el campo ruso coexisten dos tipos de contradicciones de clase: en primer lugar, las contradicciones entre los obreros agrícolas y los patronos rurales. En segundo lugar, la contradicción entre todo el campesinado y toda la clase de los terratenientes. La primera contradicción crece y se desarrolla; la segunda, se va debilitando poco a poco. La primera pertenece toda ella al futuro; la segunda, en medida considerable, al pasado. Sin embargo, para los socialdemócratas rusos, la segunda es, en la actualidad, precisamente la más esencial y la de mayor importancia práctica» (p. 417).
} 
la lucha por el socialismo a masas populares agrarias que se encontraban aún insertas en modos de producción pre-capitalistas y que, se suponía, encontrarían en el capitalismo un factor progresivo, aunque contradictorio, que las emanciparía de la opresión feudal y las absorbería en un modo de producción que constituía una etapa superior de la historia, la cual, al precio de nuevas formas de desposesión, explotación y dominio, traería consigo la creación de condiciones de necesidad y posibilidad para su superación a través del socialismo, ya con la clase obrera urbana y rural como sujeto revolucionario por excelencia. ${ }^{5}$

En esta progresión ascendente de feudalismo-capitalismo-socialismo, identificada con tres tiempos históricos sucesivos que no se concebía deseable ni posible frenar, el desarrollo capitalista aparecía como una doble necesidad: por un lado, de los campesinos mismos, para liberarse de la opresión feudal que sufrían en lo inmediato; por otro, como una estación obligada, sin la cual tampoco podían crearse condiciones objetivas y subjetivas para la liberación futura y definitiva con el socialismo. Por eso, en esta visión, cuanto más desarrollado estuviese el capitalismo -en difusión y profundidad- más cerca se estaría del socialismo. ${ }^{6}$ El indicador por excelencia de ese desarrollo era el peso social del trabajo asalariado. ${ }^{7}$

\footnotetext{
${ }^{5}$ Esta idea del campesinado como un lastre histórico «atrasado», incluso reaccionario, y con él de casi todo el mundo rural pre capitalista, «era un reflejo habitual entre los socialistas metropolitanos de Europa» [...] «hasta que estallaron las revoluciones socialistas campesinas de China y Cuba» (Williams, 2001 [1973], p. 65). Una crítica marxista a la misma idea lineal de progreso, desde la experiencia histórica latinoamericana, se puede encontrar en García Linera, (2008. pp. 23-51)

${ }^{6} \mathrm{Si}$ bien es raro encontrar en nuestros días posiciones tan lineales de «desarrollismo marxista», que hagan del desarrollo del capital una extraña bandera revolucionaria, posiciones como las de Sartelli (2010:140) aún reivindican este enfoque.

${ }^{7}$ Para Lenin (1973[1899]:247), «la manifestación principal del capitalismo agrícola [es] el empleo del trabajo asalariado». Esto tiene que ver con la definición de capitalismo en sentido estricto de Marx (1999 [1867]) para quien «lo que caracteriza la época capitalista es que la fuerza de trabajo asume, para el propio obrero, la forma de una mercancía que le pertenece, y su trabajo, por consiguiente, la forma de trabajo asalariado» (p.123). A pesar de que el debate sobre el mal llamado «capitalismo comercial» parecía saldado a principios de los años '70 (Ciafardini, 1973, p. 111), tanto las elaboraciones de Wallerstein (2006) sobre un «sistema mundo» prolongado hacia atrás hasta el siglo XV, como las más específicamente agrarias de Banaji (1997) o Bernstein (2010), sugieren la idea de que el trabajo asalariado «es solo una de las formas posibles» de explotación del trabajo por el capital y, en tanto confunden toda forma de explotación con el capitalismo y toda forma de riqueza con capital, llegan al absurdo de proponer que el Antiguo Egipto o las plantaciones esclavistas coloniales de América Latina serían distintas «formas» de capitalismo comercial.
} 
En tanto núcleo distintivo de este modo de producción, cuanto más importante fuera el trabajo asalariado en el campo, más desarrollado se encontraría el capitalismo, y más se habría superado la «cuestión agraria», en tanto ella se vinculara a las formas no-capitalistas de producción y sus sujetos en el marco de la lucha que era a la vez por el socialismo y por el progreso de la historia como tal.

Desde nuestro punto de vista, a diferencia de otros aspectos del cuerpo marxista en general, este enfoque de la cuestión agraria resulta demasiado lineal y apriorístico y, sobre todo, universaliza como modelo general una realidad muy particular -la de la Europa agraria aún en transición al capitalismo entre fines del siglo XIX y principios del XX-, de modo que, tanto en términos teóricos como históricos, no es útil para identificar la naturaleza de la cuestión agraria en países y etapas de la historia que excedan esas circunstancias específicas. Pero además de los problemas de las transiciones en el marco de las cuales se inscribe aquella vieja «cuestión agraria», hay otro problema -más contemporáneo, si se quiere- que tiene que ver con los diversos desenlaces y evoluciones posteriores de esos procesos. Para la época en que el marxismo europeo elaboraba esas reflexiones, el capitalismo no tenía demasiadas expresiones en el mundo y, a excepción de algunas particularidades nacionales, eso abonaba la idea de que el capitalismo era fundamentalmente «uno solo». Es decir, solo había un tipo de capitalismo y se asumía que ciertas singularidades de tiempo y lugar tenían que ver en todo caso con el «grado de desarrollo» de ese mismo capitalismo, del cual se esperaban resultados más o menos homogéneos allí donde se desenvolviese, mientras que todo lo que tuviese de especial se atribuía a un mayor o menor nivel de ese desarrollo y a la mayor o menor superación de «modos de producción anteriores». En pocas palabras, una cuestión de grado, que mediría hasta dónde un país estaba más o menos cerca de ese punto común, internamente homogéneo, que sería «el» capitalismo. ${ }^{8}$ En pos de captar las heterogeneidades nacionales realmente existentes, el concepto marxista de «formación económico-social» (Marx, 2007 [1857/58]; Hobsbawm, 2011 [1971]; Luporini et al., 1973) dio cuenta de las combinaciones especiales que en cada país podía tener el modo de producción

\footnotetext{
${ }^{8}$ De ahí que Lenin sintetizara teóricamente algunas de las «vías clásicas» de desarrollo capitalista en el campo, pero no llegara a dilucidar que no solo el camino, sino también el destino de las mismas, sería diferente en cada caso. Para un análisis de estas vías llamadas «clásicas» ver Azcuy Ameghino (2004, pp.137-162).
} 
capitalista con otros modos de producción -en general considerados «anteriores», lo que reforzaba tanto la idea del inevitable rumbo homogéneo hacia el capitalismo como la idea de progreso o superación que este comportaba-, pero donde el capitalismo como tal seguía siendo, básicamente, uno solo.

Sin embargo, si bien la lógica del capital es una sola, el siglo XX exhibió el desarrollo de distintos tipos de capitalismo (Azcuy Ameghino, 2011; Murmis, 1974), cualitativamente distinguibles entre sí, no solo al nivel de la articulación con otros modos de producción, como prevé el concepto de formación económico-social, sino también capitalismos internamente diferentes, con igual predominio del trabajo asalariado, pero basados en distintas ramas de producción, con diversos niveles de acumulación, estructuras de clases, tipos de sujetos sociales concretos que forman dichas clases y, fundamentalmente, disímiles posiciones en el mapa del capitalismo a escala mundial, es decir, en el cuadro más general del imperialismo (Lenin, 2016 [1916]; Beaud, 2013; Harvey, 2003). Y esto no solo porque «fronteras afuera» los países ocupen un lugar distinto en el esquema del poder global, sino porque eso supone y genera pautas distintas de funcionamiento «fronteras adentro», incluyendo sus sectores agropecuarios. De esta manera, el subdesarrollo de algunos países ya no debería asociarse a algo así como la «falta» de capitalismo, o a una especie de «atraso» en la misma línea de tiempo que los países centrales solo que en algunos casilleros anteriores. Más bien, es posible explicar el desarrollo de unos y el subdesarrollo de otros como parte de una articulación asimétrica, contradictoria y simultánea de estos distintos tipos de capitalismo bajo la lógica más general del imperialismo como sistema mundial (Marini, 2015; Ciafardini, 2014 [1984]). De modo que, mientras algunos capitalismos funcionan tomando valor generado en otros territorios para alimentar su tipo especial de desarrollo, otros se estructuran sobre la base de y para ceder valor a los primeros. De ahí que para estos últimos no sea posible esperar algún tipo de estadio superior de desarrollo -en el agro o fuera de él- a través de algo así como la superación de los modos de producción anteriores aumentando el «grado de capitalismo» de sus capitalismos -ya dominantes hace tiempo en sus formaciones sociales en términos del peso del trabajo asalariado- sino en liberarse de la naturaleza dependiente de sus capitalismos, o -acaso sería lo mejor- en liberarse del propio capitalismo.

Un primer problema de este planteo, entonces, más de cien años después y desde nuestras latitudes, es el de cómo definir la cuestión agraria 
en términos de la progresión «feudalismo-capitalismo-socialismo» cuando: 1) salvo para Europa y una parte de la América conquistada por ella, el punto de partida de esa progresión rara vez fue el feudalismo; 2) las transiciones al capitalismo llevaron distintos tipos de capitalismo en el siglo XX y, por lo tanto, a diversas problemáticas agrarias; 3) los distintos tipos de capitalismo derivados de esas transiciones, después de más de cien años de desarrollo económico, no derivaron en un advenimiento del socialismo tan rápido o mecánico como se creía y, en todo caso, jamás lo harían en base a algún tipo de maduración estructural de los mismos (más bien al contrario, como exhibió el caso cubano). En segundo lugar, está el problema del lugar del trabajo asalariado en ese esquema. Nuestra hipótesis es que, efectivamente, el mismo indica el dominio del modo de producción capitalista en una formación económico-social, cuando lo principal del valor se produce a través de este tipo de relación social de producción, sea que los trabajadores asalariados constituyan una mayoría demográfica entre los ocupados (asalarización absoluta del trabajo) o sea que, siendo una minoría, sean la principal fuerza creadora de riquezas (asalarización relativa del trabajo). Sin embargo, el predominio del trabajo asalariado puede darse por igual en distintos tipos de capitalismo y, por lo tanto, dar lugar a distintos tipos de «cuestiones agrarias». De ahí que no sea posible definir una cuestión agraria solo en términos del grado de desarrollo del capitalismo -como si este fuera de un solo tipo y creara problemas y soluciones homogéneas donde sea y cuando sea que se desenvolviese- ni medir tal desarrollo solo en términos del peso social del trabajo asalariado.

Para comprobar esta hipótesis realizamos un experimento comparativo a escala internacional: analizamos si el trabajo asalariado ocupaba el mismo lugar y revestía la misma forma en dos sectores agropecuarios capitalistas no europeos, contemporáneos, productivamente homogéneos entre sí, pero con distintas matrices históricas y asimetrías en cuanto a sus niveles de desarrollo económico general, el tipo de capitalismo del que formaban parte y la formación social más general en que se insertaban. Concretamente, comparamos el lugar de esta variable en el Corn Belt de los Estados Unidos y la Pampa Húmeda de Argentina a principios del siglo XXI: dos llanuras fértiles, ocupadas a los pueblos originarios y puestas masivamente en producción a fines del siglo XIX, que hoy producen bajo los standards de los agronegocios capitalistas básicamente los mismos commodities -maíz, soja, leche, ganado vacuno, porcino y aviar- pero que: a) se insertan en formaciones sociales y tipos de capita- 
lismo diferentes, siendo los Estados Unidos una potencia imperialista global de base industrial -aunque a la vez con un poderoso sector agropecuario- y la Argentina un país dependiente y subdesarrollado, fundamentalmente de base primario-exportadora y con un desarrollo industrial débil; b) provienen de matrices históricas diferentes en cuanto a lo específicamente agrario, siendo la del Corm Belt una estructura basada en el reparto democrático de la tierra bajo un esquema farmer-familiar y las Pampas argentinas un ejemplo de producción extensiva, basada en un inicio en la gran propiedad de la tierra; y c) el trabajo asalariado tuvo un rol visible y central en la historia agraria pampeana desde sus inicios, mientras que tuvo un rol productivo más tardío, secundario y menos claro en el medio oeste de los Estados Unidos.

\section{El trabajo asalariado en Buenos Aires}

La estructura social del trabajo agrario en Buenos Aires es bastante clara, ya que los obreros asalariados son la mayoría demográfica entre los ocupados del campo (Cuadro 1). Hasta principios del siglo XXI, su número total descendió continuamente, fruto de la mecanización agrícola (Villulla, 2015; Bocco, 1991). Sin embargo, proporcionalmente, nunca fueron menos de la mitad de la población ocupada en el ámbito rural y esa proporción creció luego de los años '70, cuando los chacareros y sus familias abandonaron los campos más rápido y en mayor proporción que los obreros, acelerando un proceso de asalarización del trabajo (Balsa, 2007). En una palabra, si bien durante todo el siglo XX disminuyó el número absoluto de trabajadores asalariados, su importancia relativa creció comparada con la de la mano de obra familiar (Villulla, 2010).

En la primera década del siglo XXI la ocupación agropecuaria total volvió a crecer un 28\%.9 Sin embargo, se profundizó la polarización social: las categorías sociales que explican este incremento son las de los empleadores y los empleados y no las de los trabajadores por cuenta propia, que siguen reduciéndose. Así, actualmente los trabajadores asalariados representan el $60 \%$ de todas las categorías ocupadas en el agro y, más específicamente, el $70 \%$ de la mano de obra propiamente dicha (es decir, sin contar a los empleadores). Así, entre 2001 y 2010, en la provincia de Buenos Aires la relación entre patrones y obreros rurales

${ }^{9}$ INDEC. Censos de Población y Vivienda, 2001 y 2010. 
pasó de 5,8 a 6 asalariados por cada propietario: un cambio cuantitativo leve, pero que consolida el perfil de esta pauta ocupacional polarizada.

\section{Cuadro $\mathrm{N}^{\circ} 1$. Población ocupada en el sector agropecuario según categoría ocupacional, provincia de Buenos Aires, 2001-2010}

\begin{tabular}{lcccccc}
\hline Categoría ocupacional & \multicolumn{2}{c}{2001} & \multicolumn{2}{c}{$\mathbf{2 0 1 0}$} & Diferencia & Variación \\
\hline Obreros & 94.871 & 58 & 126.182 & 60 & 31.311 & 33 \\
Patrón & 22.141 & 13 & 31.037 & 15 & 8.896 & 40,2 \\
Trabajador por cuenta propia & 36.099 & 22 & 43.127 & 20 & 7.028 & 19,5 \\
Trabajador familiar con sueldo & 3.526 & 2 & & 0 & -3.526 & -100 \\
Trabajador familiar sin sueldo & 8.308 & 5 & 10.857 & 5 & 2.549 & 30,7 \\
Totales & 164.945 & 100 & 211.203 & 100 & 46.258 & 28 \\
\hline
\end{tabular}

Fuente: INDEC. Censos de Población y Vivienda, 2010

Si bien está claro el predominio del trabajo asalariado en la producción agropecuaria de Buenos Aires, identificar en qué tipo de cultivos o establecimientos se emplea esta mayoría demográfica de asalariados y qué proporción de la producción depende de ellos, no es tan simple de verificar. Básicamente porque no existen estadísticas actualizadas ni bien ordenadas al respecto. ${ }^{10}$ Eso nos exige un esfuerzo extra para rearmar una imagen coherente del conjunto, sobre la base de investigaciones parciales e información fragmentaria.

En el conjunto de la zona pampeana (que además de la provincia de Buenos Aires incluye a Santa Fe, Córdoba, La Pampa y Entre Ríos) se contabilizan 293.494 trabajadores asalariados. Alrededor de 60.000 de estos obreros se emplearían en la agricultura extensiva, mientras que 80.000 se ocuparían en la ganadería vacuna. ${ }^{11}$ La otra mitad de los empleados agrarios estaría empleada en actividades escasamente mecanizadas, como la horticultura, o más intensivas, como la lechería y la cría de pollos y cerdos. La provincia de Buenos Aires ocupa el $42 \%$ de todos los obreros rurales de la región, reproduciendo en términos generales las proporciones entre las distintas actividades que se desarrollan allí: $20 \%$ agricultura, $30 \%$ ganadería, $50 \%$ producciones intensivas.

\footnotetext{
${ }^{10}$ El último censo agropecuario es de 2002 y el censo de población no desagrega las ramas productivas al interior del sector agropecuario.

${ }^{11}$ Ministerio de Trabajo, Empleo y Seguridad Social de la Nación. Observatorio de Empleo y Dinámica Empresarial. Ministerio de Trabajo, Empleo y Seguridad Social de la Nación.
} 
Respecto a su rol concreto en los establecimientos, reelaboramos datos primarios del censo agropecuario de 2002 sobre qué tareas hacía en los campos cada tipo de trabajador -familiar o asalariado- sin contar el trabajo de los titulares. Es decir, solo se preguntó por el trabajo de personal subordinado. El resultado fue claro: el $80 \%$ del trabajo manual sobre el que preguntó el censo (operación de maquinaria, equipos e instalaciones; operación de ordeñadoras y otras instalaciones de tambo; tareas generales de peón; y mediería hortícola o tambera) era realizado por obreros asalariados (ver Cuadro 2). A su vez, el $84 \%$ de los obreros asalariados se dedicaba a este tipo de tareas manuales (ver Cuadro 3), mientras que solo un $16 \%$ de asalariados de «cuello blanco» realizaba trabajos de gestión o dirección. Estos datos, que representan un paneo a nivel micro de todas las explotaciones agropecuarias independientemente de su producción o escala, permiten establecer una fuerte correlación general entre trabajo manual y trabajo asalariado en el agro pampeano. Si los cruzamos con los primeros datos que analizábamos del censo de población, no sería incorrecto inferir que los asalariados no solo son una mayoría demográfica entre los trabajadores del sector, sino que, cuando son empleados, son empleados para hacer las tareas manuales del campo.

Cuadro 2. Tipo de trabajo según tipo de trabajador. Región pampeana, 2002.

\begin{tabular}{ccc}
\hline & \multicolumn{2}{c}{ Tipo de trabajo } \\
\hline Tipo de trabajador & Manual & No manual \\
Familiar & $23 \%$ & $34 \%$ \\
Asalariado & $77 \%$ & $66 \%$ \\
& $100 \%$ & $100 \%$ \\
\hline
\end{tabular}

Fuente: INDEC. Censo Nacional Agropecuario, 2002 


\section{Cuadro 3. Tipo de trabajador según tipo de trabajo. Región pampeana, 2002.}

\begin{tabular}{lcc}
\hline & \multicolumn{2}{c}{ Tipo de trabajador } \\
\hline Tipo de trabajo & Familiar & Asalariado \\
Manual & $73 \%$ & $84 \%$ \\
No manual & $27 \%$ & $16 \%$ \\
& $100 \%$ & $100 \%$ \\
\hline
\end{tabular}

Fuente: INDEC. Censo Nacional Agropecuario, 2002

Puntualmente en la agricultura existe un alto nivel de tercerización del trabajo asalariado, a través del contratismo de servicios (Lombardo y Tort, 2018; Villulla, 2016). Según el censo agropecuario de 2002, en el conjunto de la provincia de Buenos Aires el $60 \%$ de la superficie era cosechada a través de alguna forma de contratismo. ${ }^{12}$ Para 2008, otras fuentes indicaban que hasta un $80 \%$ de las cosechas de granos era organizado por contratistas, del mismo modo que el $65 \%$ de las tareas de siembra y aplicación de agroquímicos en todo el país. ${ }^{13} \mathrm{~A}$ su vez, de acuerdo a estadísticas oficiales de la provincia de Buenos Aires, en promedio, el $63 \%$ de los trabajadores de las empresas contratistas son asalariados permanentes y/o transitorios (ver Cuadro 4). Además, las estadísticas no indican que los propietarios y sus familias trabajen en sentido estricto, sino que solo son contabilizados como los dueños de las maquinarias, de modo que, teniendo en cuenta la información de los cuadros 2 y 3 , es posible la proporción de los asalariados entre quienes realizan el trabajo manual en estas firmas sea mayor.

${ }^{12}$ INDEC. Censo Nacional Agropecuario, 2002.

${ }^{13}$ Federación Argentina de Contratistas de Maquinaria Agrícola (FACMA), Anuario. Casilda, Argentina: 2008. 
Cuadro 4. Estructura social del trabajo en las empresas contratistas. Buenos Aires, 2001-2015*

\begin{tabular}{lcccccccc}
\hline & $\mathbf{2 0 0 1 /}$ & $\mathbf{2 0 0 2 /}$ & $\mathbf{2 0 0 3 /}$ & $\mathbf{2 0 0 4}$ & $\mathbf{2 0 0 5 /}$ & $\mathbf{2 0 1 2 /}$ & $\mathbf{2 0 1 3 /}$ & $\mathbf{2 0 1 4 /}$ \\
\hline Propietarios y & $41 \%$ & $\mathbf{2 0 0 3}$ & $\mathbf{2 0 0 4}$ & $\mathbf{2 0 0 5}$ & $\mathbf{2 0 0 6}$ & $\mathbf{2 0 1 3}$ & $\mathbf{2 0 1 4}$ & $\mathbf{2 0 1 5}$ \\
familiares & 46 & $35 \%$ & $35 \%$ & $31 \%$ & $37,90 \%$ & $38,50 \%$ & $39,70 \%$ \\
Empleados & $59 \%$ & $64 \%$ & $65 \%$ & $65 \%$ & $69 \%$ & $62,10 \%$ & $61,50 \%$ & $60,30 \%$ \\
Totales & $100 \%$ & $100 \%$ & $100 \%$ & $100 \%$ & $100 \%$ & 100 & 100 & 100 \\
\hline
\end{tabular}

Fuente: Dirección Provincial de Estadísticas. Encuesta Provincial de Servicios Agropecuarios de la Provincia de Buenos Aires (EPSABA), 2002-2016.

${ }^{*}$ Sin datos disponibles para 2006/07 y 2011/12.

Esta tercerización del trabajo mecanizado es practicada tanto por los grandes capitales del sector como por pequeños y medianos chacareros sin capital, que pagan por los servicios de siembra, aplicación de agroquímicos o cosecha, en vez de comprar y operar ellos mismos la maquinaria. Sin embargo, un estudio de Lódola y Brigo (2013) indica que el $80 \%$ de la demanda de contratistas se explica solo por grandes firmas concentradas, integradas en fideicomisos o asociaciones con bancos e industrias. De acuerdo a Barsky y Dávila (2008) este tipo de firmas componen un $10 \%$ de explotaciones de más de 1.000 hectáreas que controla la comercialización del $80 \%$ de la soja argentina y el cultivo de no menos de 3 millones de hectáreas en todo el país.

Esto nos indica que, en términos absolutos, la agricultura de granos es poco demandante de mano de obra dada su base técnica (trabajo altamente mecanizado) y por eso no emplea más del $20 \%$ de los obreros rurales bonaerenses, pero, en términos relativos, no escapa al predominio general del trabajo asalariado. Como vimos, entre el 60\% y $70 \%$ de su mano de obra -entre la ocupada en empresas contratistas y la que se emplea directamente en grandes explotaciones- trabaja en relación de dependencia. De modo que si no hay más obreros ocupados en el cultivo de los suelos no es por el predominio de la mano de obra familiar, sino por las características del proceso de trabajo mecanizado, que simplemente no demanda más gente para su producción. Así, hasta en los rubros en que hay menos obreros, como la agricultura, los asalariados son la mayoría social, al igual que en el conjunto de las producciones. Esto significa que la asalarización del trabajo en el campo bonaerense es absoluta: porque los obreros asalariados comportan una mayoría demo- 
gráfica entre los ocupados del sector y porque a la vez representan la principal fuerza creadora de valor.

\section{El trabajo asalariado en Iowa}

El papel de los trabajadores asalariados en el agro de Iowa es menos claro que en Buenos Aires. Básicamente, porque no son la mayoría demográfica entre los ocupados en el sector. En efecto, en el año 2012, el censo agropecuario de Estados Unidos registró 129.624 operadores a cargo de las decisiones en las 88.637 granjas de Iowa y 79.838 trabajadores asalariados (25.620 permanentes y 54.218 transitorios). Es decir que, en el promedio general, para el censo agropecuario los operadores constituían prácticamente el $62 \%$ de los ocupados en el sector y los asalariados, solo un 38\% (ver Cuadro 5), coincidiendo con la pauta nacional, en donde dos tercios de los ocupados en el agro de Estados Unidos serían granjeros familiares y solo un tercio obreros asalariados (Hertz, 2016).

Cuadro 5. Población ocupada en el sector agropecuario, según categoría ocupacional, Iowa, 2012

\begin{tabular}{lcc}
\hline Operadores & 129.644 & 61,9 \\
\hline Principal & 88.637 & 42,3 \\
Segundo & 35.435 & 16,9 \\
Tercero & 5.572 & 2,7 \\
\hline Asalariados & 79.838 & 38,1 \\
\hline Permanentes & 25.620 & 12,2 \\
Transitorios & 54.218 & 25,9 \\
Total & 209.482 & 100 \\
\hline
\end{tabular}

Fuente: elaboración propia en base a USDA, Census of Agriculture 2012

Cabe observar, sin embargo, que la categoría de operador utilizada por el censo agropecuario norteamericano no es equivalente a la de un farmer independiente. Por lo tanto, agranda artificialmente el peso de esta ambigua figura social frente a los empleados. Eso es así porque, en primer lugar, la categoría de operador incluye a la capa superior de los 
asalariados: los managers calificados, que operan el conjunto de una granja a cambio de un salario, en relación de dependencia. En segundo lugar, porque esta categoría suma a las segundas y terceras líneas de operadores en esta condición, lo cual suele incluir a las familias de los managers que se emplean en estas explotaciones, todos ellos también en relación de dependencia. En tercer lugar, la categoría incluye también a empleadores netos de trabajo asalariado, que no están distinguidos de los trabajadores familiares ni de los managers. Así, si releemos el Cuadro 5, veremos que la cantidad de operadores principales coincide con la cantidad total de granjas en Iowa. Naturalmente, «alguien toma las decisiones» en cada una de las granjas. Pero eso no hace de todos los que «toman decisiones» granjeros familiares: en algunos casos se trata de empresarios capitalistas, en otros del directorio de una granja corporativa, un gran inversor o de un manager a sueldo. En efecto, de las 88.637 granjas registradas en Iowa en 2012, el 15\% eran establecimientos no exactamente familiares: 7.189 eran corporativas, 4.987 eran sociedades y 1.789 eran firmas cooperativas, estatales, institucionales u otras. El hecho es que la categoría de operador reúne a todas estas figuras, muy distintas entre sí, incluyendo a empleados y empleadores y que, sumando a las familias y a las segundas y terceras líneas de «decisión», multiplican artificialmente tanto su peso social -en términos cuantitativos- como su carácter «familiar», en términos cualitativos. Pero, en pocas palabras, ni son tantos ni son tan familiares.

Hechas estas salvedades, es cierto que solo un $31,5 \%$ de las granjas de Iowa emplea trabajadores asalariados, al menos tal y como los entiende el censo. El resto es atendido por diversas modalidades de trabajo familiar o por cuenta propia. Sin embargo, no todas las farms tienen el mismo peso productivo. Si bien solo el $31,5 \%$ de ellas emplea obreros, en este subgrupo se encuentran el 18,6\% de los establecimientos que explican hasta el $80 \%$ de la facturación agropecuaria de Iowa (ver Cuadro 6). Ciertamente, entre estas firmas de mayor facturación -más de 1 millón de dólares anuales- el $77 \%$ sí emplea mano de obra asalariada y del mismo modo lo hace el $60 \%$ de las granjas del estrato que le sigue en facturación anual (entre 500.000. y 999.999 dólares anuales). Estas dos categorías superiores componen por sí solas el $40 \%$ de todas las granjas que demandan trabajo asalariado en Iowa, y explican el 82,9\% de todos los fondos desembolsados en mano de obra (ver Cuadro 7). 
Cuadro 6. Ventas de las granjas por estrato de facturación, Iowa. 2012

\begin{tabular}{lcccc}
\hline \multicolumn{1}{c}{$\begin{array}{c}\text { Estrato de } \\
\text { facturación }\end{array}$} & Granjas & $\begin{array}{c}\text { Ventas en } \\
\text { miles u } \$ \mathbf{s}\end{array}$ & Granjas & Ventas \\
\hline$\$ 1.000 .000$ o mas & 6.919 & 17.652 .127 & 7,8 & 57,3 \\
$\$ 500.000$ a $\$ 999.999$ & 9.637 & 7.035 .084 & 10,9 & 22,8 \\
$\$ 250.000$ a $\$ 499.999$ & 9.769 & 3.559 .383 & 11 & 11,5 \\
$\$ 100.000$ a $\$ 249.999$ & 10.036 & 1.666 .502 & 11,3 & 5,4 \\
$\$ 50.000$ a $\$ 99.999$ & 7.470 & 547.324 & 8,4 & 1,8 \\
$\$ 25.000$ a $\$ 49.999$ & 5.775 & 210.932 & 6,5 & 0,7 \\
$\$ 10.000$ a $\$ 24.999$ & 6.041 & 99.521 & 6,8 & 0,3 \\
$\$ 5.000$ a $\$ 9.999$ & 4.328 & 30.997 & 4,9 & 0,1 \\
$\$ 2.500$ a $\$ 4.999$ & 3.613 & 13.101 & 4,1 & 0,04 \\
$\$ 1.000$ a $\$ 2.499$ & 3.206 & 5.356 & 3,6 & 0,02 \\
Menos de $\$ 1.000$ & 21.843 & 1.204 & 24,6 & 0,004 \\
Totales & 88.637 & 30.821 .532 & 100 & 100 \\
\hline
\end{tabular}

Fuente: elaboración propia en base a Census of Agriculture 2012, Departamento de Agricultura de los Estados Unidos. 
Cuadro 7. Granjas con trabajo asalariado y gastos en trabajo asalariado, según estrato de facturación de las granjas, Iowa. 2012

\begin{tabular}{|c|c|c|c|c|}
\hline \multirow{2}{*}{$\begin{array}{l}\text { Estrato de facturación } \\
\$ 1000.000 \text { o mas }\end{array}$} & \multirow{2}{*}{$\begin{array}{c}\begin{array}{c}\text { Total de } \\
\text { granjas }\end{array} \\
6.919\end{array}$} & \multicolumn{2}{|c|}{$\begin{array}{c}\text { Granjas con trabajo } \\
\text { asalariado en el } \\
\text { estrato }\end{array}$} & \multirow{2}{*}{$\begin{array}{c}\begin{array}{c}\text { Gastos en } \\
\text { trabajo } \\
\text { asalariado }\end{array} \\
64,7\end{array}$} \\
\hline & & 5.321 & 76,9 & \\
\hline$\$ 500.000$ a $\$ 999.999$ & 9.637 & 5.728 & 59,4 & 18,2 \\
\hline$\$ 250.000$ a $\$ 499.999$ & 9.769 & 4.302 & 44 & 7,3 \\
\hline$\$ 100.000$ a $\$ 249.999$ & 10.036 & 3.229 & 32,2 & 4,1 \\
\hline$\$ 50.000$ a $\$ 99.999$ & 7.470 & 1.880 & 25,2 & 1,8 \\
\hline$\$ 25.000$ a $\$ 49.999$ & 5.775 & 1.232 & 21,3 & 0,7 \\
\hline$\$ 10.000$ a $\$ 24.999$ & 6.041 & 1.145 & 19 & 0,6 \\
\hline$\$ 5.000$ a $\$ 9.999$ & 4.328 & 683 & 15,8 & 0,4 \\
\hline$\$ 2.500$ a $\$ 4.999$ & 3.613 & 517 & 14,3 & 0,2 \\
\hline$\$ 1.000$ a $\$ 2.499$ & 3.206 & 457 & 14,3 & 0,3 \\
\hline Menos de $\$ 1.000$ & 21.843 & 3.412 & 15,6 & 1,6 \\
\hline Todas las granjas & 88.637 & 27.906 & 31,5 & 100 \\
\hline
\end{tabular}

Fuente: elaboración propia en base a Census of Agriculture 2012, Departamento de Agricultura de los Estados Unidos.

Independientemente del tipo de producción que comercializaron estas granjas, lo que quieren decir estos datos es que su importancia productiva -que, insistimos, alcanza el $80 \%$ de los valores comercializados- es en realidad la importancia productiva de sus trabajadores asalariados, que realizaron en términos prácticos el trabajo de creación de riquezas en estas empresas decisivas para el agro de Iowa.

Por el contrario, la mayoría de las farms, que son más pequeñas y naturalmente más numerosas, registran las tasas más bajas de empleo. Es decir, que casi nunca contratan asalariados y, cuando lo hacen, los contratan en cantidades también pequeñas. Pero todas ellas no explican más del $20 \%$ de la facturación del estado. Y, más específicamente, la mitad de las granjas de Iowa $(50,5 \%)$ que facturan menos de $\$ 50.000$ al año y casi no empelan obreros, explican solo el 3\% de la facturación estatal. En palabras duras: en un Iowa dominado por el agronegocio, 
todo ese trabajo familiar o por cuenta propia que constituye la mayoría demográfica de los ocupados es productivamente irrelevante; mientras que los asalariados, que son una minoría, explican alrededor del $80 \%$ de la facturación rural, empleados por granjas capitalistas.

Se trata de cálculos de mínima, ya que, a diferencia de los datos que podíamos triangular en Argentina, la estadística del Departamento de Agricultura de los Estados Unidos no permite ponderar cuánto trabajo asalariado agrega el equivalente al contratismo de servicios argentino, el customwork, a las granjas que lo emplean. Lo que sí se sabe es que el customwork es empleado por el 36,6\% de las granjas de Iowa. Es decir, se usa más que el trabajo asalariado puro. Y al contrario que en Argentina, los establecimientos económicamente más relevantes no explican una proporción tan importante de la demanda de estos servicios: solo un $13,8 \%$ entre ella apela al customwork, aunque esa proporción de granjas reúne, junto al $14,8 \%$ del estrato inmediatamente inferior, el $64 \%$ de todos los gastos en este rubro.

Volviendo al trabajo asalariado, decíamos que la proporción de los gastos en este rubro que acaparan las granjas más grandes es muy importante: solo el estrato superior explica el $64,7 \%$ del dinero invertido en salarios rurales de todo Iowa, mientras junto al estrato inmediatamente inferior abarcan el $82,9 \%$ de todos los fondos desembolsados en mano de obra. De todos modos, estas empresas no concentran una proporción de trabajadores $(32,5 \%)$ tan importante como la cantidad de dinero que invierten en ellos $(64,7 \%)$, como puede verse en el Cuadro 8. 
Cuadro 8. Gastos en trabajo asalariado y de trabajadores asalariados por granjas según estrato de facturación, Iowa. 2012

\begin{tabular}{lrrrr}
\hline \multicolumn{1}{c}{$\begin{array}{c}\text { Estrato de } \\
\text { facturación }\end{array}$} & $\begin{array}{c}\text { Gastos en trabajo } \\
\text { asalariado }\end{array}$ & \multicolumn{2}{c}{$\begin{array}{c}\text { Trabajadores } \\
\text { asalariados }\end{array}$} \\
\hline$\$ 1.000 .000$ o mas & $\$ 451.571$ & 64,7 & 25929 & 32,5 \\
$\$ 500.000$ a $\$ 999.999$ & $\$ 127.100$ & 18,2 & 15360 & 19,2 \\
$\$ 250.000$ a $\$ 499.999$ & $\$ 51.027$ & 7,3 & 10036 & 12,6 \\
$\$ 100.000$ a $\$ 249.999$ & $\$ 28.871$ & 4,1 & 7981 & 10 \\
$\$ 50.000$ a $\$ 99.999$ & $\$ 12.304$ & 1,8 & 4599 & 5,8 \\
$\$ 25.000$ a $\$ 49.999$ & $\$ 4.953$ & 0,7 & 2694 & 3,4 \\
$\$ 10.000$ a $\$ 24.999$ & $\$ 4.377$ & 0,6 & 2647 & 3,3 \\
$\$ 5.000$ a $\$ 9.999$ & $\$ 2.608$ & 0,4 & 1682 & 2,1 \\
$\$ 2.500$ a $\$ 4.999$ & $\$ 1.444$ & 0,2 & 1216 & 1,5 \\
$\$ 1.000$ a $\$ 2.499$ & $\$ 2.186$ & 0,3 & 1002 & 1,3 \\
Menos de $\$ 1.000$ & $\$ 11.279$ & 1,6 & 6692 & 8,4 \\
Todas las granjas & $\$ 697.720$ & 100 & 79838 & 100 \\
\hline
\end{tabular}

Fuente: elaboración propia en base a Census of Agriculture 2012, Departamento de Agricultura de los Estados Unidos.

Lo que sucede es que en Iowa los trabajadores del campo son más temporarios que permanentes. En efecto, los primeros (54.218) prácticamente doblan a los segundos (25.620), tanto en la cantidad de trabajadores de uno y otro tipo, como en la cantidad de granjas que emplean trabajo temporario (20.219) respecto al regular (11.099). Esto tiene que ver con la importancia de la agricultura extensiva en el estado, con el alto grado de mecanización e intensificación del trabajo agrícola -con su consecuente ahorro de puestos de trabajo y acortamiento de los tiempos de labor- y con la mayor asociación al tradicional cultivo de maíz de las granjas más pequeñas o medianas. No obstante, si bien este es el perfil global básico del trabajo asalariado en la zona, lo que puede observarse en los cuadros 9 y 10, es que la relación entre trabajo permanente y transitorio se invierte en las explotaciones más grandes: aquí, es el primero el que predomina sobre el segundo. Y esto explica por qué la pro- 
porción de gastos en fuerza de trabajo de estas grandes empresas $(64,7 \%)$ no se refleja también en la proporción de asalariados que contratan: 32,4\%. Lo que sucede, básicamente, es que estas unidades mayores emplean a los obreros por más tiempo. Eventualmente, por el doble de tiempo que la media de las granjas de Iowa. Lo cual, naturalmente, duplica también los gastos en trabajo asalariado en este estrato superior sin aumentar en la misma medida la cantidad de empleados. En efecto, los dos estratos superiores de facturación explican el 73\% de todo el trabajo rural permanente en el área. Eso no quiere decir que no empleen también trabajadores temporarios. De hecho, emplean el $40 \%$ de los operarios estacionales, siendo por lo tanto los principales demandantes de trabajo temporario también. Pero el hecho es que las firmas más grandes emplean más trabajadores permanentes que transitorios: a la inversa que todo el resto de las categorías inferiores de granjas y al contrario del perfil global del estado de Iowa. Esta pauta diferencial de empleo de las granjas productivamente más importantes tiene que ver, por un lado, con sus altos niveles de acumulación y reinversión de capital y, por otro, con que las tareas para las que son empleados los trabajadores en estas grandes firmas no se reducen solo al cultivo del suelo, sino que requieren el cuidado mucho más regular de animales -sean cerdos, vacunos o pollos- en su mayoría criados en regímenes de confinamiento. Es decir, toda una diversidad de actividades y no solo la producción de maíz. De hecho, según los datos del censo agropecuario de 2012, en la facturación de ese 7,8\% de las granjas con más de 1 millón de dólares anuales, los cerdos -y no los granos- encabezan el ranking de ventas, explicando el $34 \%$ de las mismas. El maíz, por su parte, comporta el $27 \%$ de lo comercializado por esta cúpula, mientras que la soja no supera el $10 \%$ de sus ingresos. Hasta la ganadería vacuna está por encima de la oleaginosa explicando un $17 \%$ de su facturación, quedando para el final la producción de pollos y huevos con un $7 \%$. 
Cuadro 9. Trabajadores permanentes y transitorios por granja, según estrato de facturación, Iowa. 2012

\begin{tabular}{|c|c|c|c|c|}
\hline \multirow[t]{2}{*}{ Estrato de facturación } & \multicolumn{2}{|c|}{$\begin{array}{l}\text { Trabajadores } \\
\text { permanentes }\end{array}$} & \multicolumn{2}{|c|}{$\begin{array}{c}\text { Trabajadores } \\
\text { transitorios }\end{array}$} \\
\hline & Totales & $\%$ & Totales & $\%$ \\
\hline$\$ 1.000 .000$ o mas & 13.814 & 53,9 & 12.115 & 22,3 \\
\hline$\$ 500.000$ a $\$ 999.999$ & 4.924 & 19,2 & 10.436 & 19,2 \\
\hline$\$ 250.000$ a $\$ 499.999$ & 2.302 & 9 & 7.734 & 14,3 \\
\hline$\$ 100.000$ a $\$ 249.999$ & 1.483 & 5,8 & 6.498 & 12 \\
\hline$\$ 50.000$ a $\$ 99.999$ & 691 & 2,7 & 3.908 & 7,2 \\
\hline$\$ 25.000$ a $\$ 49.999$ & 396 & 1,5 & 2.298 & 4,2 \\
\hline$\$ 10.000$ a $\$ 24.999$ & 352 & 1,4 & 2.295 & 4,2 \\
\hline$\$ 5.000$ a $\$ 9.999$ & 198 & 0,8 & 1.484 & 2,7 \\
\hline$\$ 2.500$ a $\$ 4.999$ & 137 & 0,5 & 1.079 & 2 \\
\hline$\$ 1.000$ a $\$ 2.499$ & 154 & 0,6 & 848 & 1,6 \\
\hline Menos de $\$ 1.000$ & 1.169 & 4,6 & 5.523 & 10,2 \\
\hline Todas las granjas & 25.620 & 100 & 54.218 & 100 \\
\hline
\end{tabular}

Fuente: elaboración propia en base a Census of Agriculture 2012, Departamento de Agricultura de los Estados Unidos 
Cuadro 10. Granjas con trabajadores permanentes según estrato de facturación, Iowa. 2012

\begin{tabular}{|c|c|c|c|c|}
\hline \multirow[t]{2}{*}{$\begin{array}{l}\text { Estrato de } \\
\text { facturación }\end{array}$} & \multicolumn{2}{|c|}{$\begin{array}{l}\text { Granjas con } \\
\text { trabajadores } \\
\text { permanentes }\end{array}$} & \multicolumn{2}{|c|}{$\begin{array}{c}\text { Granjas con } \\
\text { trabajadores } \\
\text { transitorios }\end{array}$} \\
\hline & Totales & $\%$ & Totales & $\%$ \\
\hline$\$ 1.000 .000$ o mas & 3.566 & 32,1 & 3.698 & 18,3 \\
\hline$\$ 500.000$ a $\$ 999.999$ & 2.712 & 24,4 & 4.217 & 20,9 \\
\hline$\$ 250.000$ a $\$ 499.999$ & 1.567 & 14,1 & 3.278 & 16,2 \\
\hline$\$ 100.000$ a $\$ 249.999$ & 964 & 8,7 & 1.540 & 7,6 \\
\hline$\$ 50.000$ a $\$ 99.999$ & 508 & 4,6 & 1.481 & 7,3 \\
\hline$\$ 25.000$ a $\$ 49.999$ & 302 & 2,7 & 1.001 & 5 \\
\hline$\$ 10.000$ a $\$ 24.999$ & 221 & 2 & 966 & 4,8 \\
\hline$\$ 5.000$ a $\$ 9.999$ & 134 & 1,2 & 579 & 2,9 \\
\hline$\$ 2.500$ a $\$ 4.999$ & 106 & 1 & 434 & 2,1 \\
\hline$\$ 1.000$ a $\$ 2.499$ & 101 & 0,9 & 380 & 1,9 \\
\hline Menos de $\$ 1.000$ & 918 & 8,3 & 2.645 & 13,1 \\
\hline Todas las granjas & 11.099 & 100 & 20.219 & 100 \\
\hline
\end{tabular}

Fuente: elaboración propia en base a Census of Agriculture 2012, Departamento de Agricultura de los Estados Unidos.

En el promedio general de Iowa, suele concluirse que los trabajadores asalariados son una especie de «accesorio» secundario del trabajo farmer porque, tomando a los operadores como farmers y a todos los farmers como si aportaran la misma proporción a la producción de riquezas, habría solo 0,6 asalariados por cada operador. Y si se toman en cuenta las granjas en vez de los operadores, el promedio de asalariados por granja no pasa de 0,9 . Con estas estadísticas, pareciera comprobarse que la producción de granos y carnes del estado se basara en el trabajo familiar y que el agronegocio es compatible con sus valores y su cultura. Pero si tomamos la cantidad de empleados ocupados en Iowa por la cantidad de empleadores, la relación trepa a casi 3 asalariados por patrón. Y lo más importante, si tomamos solo a las granjas más «exitosas» de acuerdo a los propios parámetros del agronegocio capitalista -es de- 
cir, el 7,8\% que facturó el $60 \%$ de la producción de Iowa- encontramos que la relación entre trabajadores y empleadores es de casi 5 obreros por cada patrón, a solo un paso del promedio general que señalábamos en las pampas argentinas (6 obreros por patrón).

En síntesis, entonces, puede comprobarse que las firmas de mayor envergadura económica -las que explican la producción agrícola/ganadera de Iowa- se basan en el empleo de trabajadores asalariados. Esta forma de asalarización del trabajo es relativa: los obreros asalariados no son una mayoría demográfica entre los ocupados en el sector, pero sí son los principales productores directos del agro de Iowa.

\section{Reflexiones finales}

Hemos verificado que, en el sentido más estricto del término, el capitalismo es el modo de producción dominante tanto en el agro de la Pampa Húmeda argentina como en el del Corn Belt estadounidense. Se trata de dos sectores agropecuarios claramente capitalistas, en los que las proporciones decisivas de la producción son desarrolladas por trabajadores asalariados. En el caso argentino, la asalarización del trabajo es absoluta: además de ser los principales productores directos, los obreros asalariados son una mayoría demográfica entre los ocupados del sector. En el caso norteamericano, la asalarización del trabajo es solo relativa, ya que, si bien los obreros asalariados también se revelan como los principales productores directos, constituyen una minoría demográfica frente al todavía denso universo de granjeros propietarios.

El predominio productivo del trabajo asalariado es lo que tienen de común ambos sectores agropecuarios y los que los define como capitalistas. Sin embargo, limitar la cuestión agraria al «grado de desarrollo del capitalismo» y medir el mismo por «el peso del trabajo asalariado» llevaría a equívocos importantes a la hora de caracterizar con exactitud una estructura social agraria de modo más integral, así como de identificar y explicar sus problemáticas específicas y prefigurar posibles soluciones y sujetos de cambio.

En primer lugar, en los términos en que se planteaba originalmente como parte de los procesos de transición al capitalismo, esa interpretación daría por resuelta aquella vieja cuestión agraria, pero se revelaría incapaz de trazar las coordenadas de una nueva, contemporánea, una vez que el capitalismo ya se ha instituido como modo de producción 
dominante, pero aún se mantiene la presencia -y hasta el predominio demográfico, como en los Estados Unidos- de una multiplicidad de actores que no se reducen a «bugueses y proletarios» y de una serie de problemáticas que tampoco se agotan en relaciones capital-trabajo, sino que abracan conflictos y problemáticas vinculadas al uso, el deterioro y la apropiación de la tierra, el agua y la naturaleza en general; las disputas por la distribución social de la renta o por el reclamo de subsidios; luchas campesinas -como en el caso argentino- e indígenas que, aunque no comprometan a los principales actores «productivos» del agro, son parte de los problemas de los sectores populares que genera precisamente el desarrollo -y no el «atraso»- del capitalismo; del mismo modo que las poblaciones afectadas por intoxicaciones o la concentración económica que excluye a distintas formas de pequeña y mediana producción, con sus efectos multiplicadores en las cadenas de valor nacionales y regionales. ${ }^{14}$

En segundo lugar, la vieja interpretación unilateral pasaría por alto las especificidades que le da a cada sector agropecuario el tipo de capitalismo y la formación social más general de la que forma parte, junto a toda otra serie de variables económicas, políticas y culturales que quedarían subsumidas por una aparente homogeneidad estructural entre el agro pampeano y el del medio oeste norteamericano, determinada sólo por el lugar productivo del trabajo asalariado. Es más, este criterio podría llegar aún más lejos: a juzgar por el peso mayor del trabajo asalariado en las pampas respecto al midwest, sería posible concluir que el agro criollo es más capitalista y por lo tanto más «desarrollado» que el del norte. Difícil de sostener. Y, sin embargo, se trata de una conclusión absolutamente lógica en los términos de aquella vieja visión lineal, que solo observaba diferencias de grado de una sola variable, sin dar cuenta de diversidades de índole cualitativa para explicar cómo y por qué, precisamente por los tipos distintos de capitalismo y de formación social más global de las que forman parte, y aún en los términos en que el «desarrollo» es planteado por el capitalismo (cantidades de producción, índices de productividad, magnitud de la acumulación total, niveles medios de capitalización, infraestructura general, integración vertical y horizontal de los capitales y las cadenas de valor, superficie cultivada sobre la super-

\footnotetext{
${ }^{14}$ Algunas propuestas originales para repensar en esta clave la nueva cuestión agraria desde en nuestra época y nuestra región en: Azcuy Ameghino (2016); Felício (2014) y Stédile (2006).
} 
ficie cultivable, etc.), un agro con asalarización absoluta del trabajo como el pampeano puede ser, a la vez, menos desarrollado que uno con asalarización relativa como el del Corn Belt.

En tercer lugar, si la cuestión agraria es enfocada a partir de dar cuenta de las problemáticas que un régimen plantea a las mayorías populares agrarias concretas, tampoco alcanza con identificar a los principales productores directos de valor. De otro modo, no se trataría de un problema social y político, sino de uno económico en sentido estrecho. En esta línea, si en el caso de la zona pampeana las mayorías populares agrarias y los principales creadores de valor sí se yuxtaponen en una misma figura social -la de los obreros rurales-, en el caso del midwest norteamericano esto no es así, ya que las mayorías propiamente dichas se componen de un mosaico mucho más heterogéneo y difuso de pequeños y medianos propietarios o, más específicamente, agricultores familiares o por cuenta propia capitalizados, mientras que los principales productores directos representan una minoría demográfica, lo cual hace volver a foja cero -aunque en nuevas condiciones históricas- la problemática inicial que Kautsky atribuía a la persistencia de formas no-capitalistas de producción y la necesidad de elaborar un programa que las contuviera de modo de construir una nueva mayoría política para un proyecto de cambio eficaz.

\section{Referencias bibliográficas}

Azcuy Ameghino, E. (1997). Buenos Aires, Iowa, y el desarrollo agropecuario en las pampas y praderas. Cuadernos del PIEA, (3).

Azcuy Ameghino, E. (2004). Los caminos clásicos del desarrollo histórico del capitalismo agrario. En E. Azcuy Ameghino. Trincheras en la Historia, pp.137-162. Buenos Aires, Argentina: Imago Mundi

Azcuy Ameghino, E. (2011). Una historia casi agraria. Buenos Aires, Argentina: Ediciones del PIEA.

Azcuy Ameghino, E. (2016). La cuestión agraria en Argentina. Caracterización, problemas y propuestas. Revista Interdisciplinaria de Estudios Agrarios, (45), 5-51.

Azcuy Ameghino, E. (2010). Estructura de las explotaciones agropecuarias y niveles de producción agrícola: los casos de Iowa y Pergamino, 1987-1988. En J.M. Villulla y D.A. Fernández (Comps.). So- 
bre la tierra. Problemas del desarrollo agropecuario pampeano, pp.2756. Buenos Aires, Argentina: Facultad de Ciencias Económicas de la Universidad de Buenos Aires.

Balsa, J. (2003). La concentración de la agricultura entre 1937 y 1988 : el cornbelt y la pampa maicera argentina. Boletín del Instituto de Historia Argentina y Americana «Dr. Emilio Ravignani», (25), 121-156. Balsa, J. (2007). El desvanecimiento del mundo chacarero. Transformaciones sociales en la agricultura bonaerense, 1937-1988. Bernal, Argentina: Universidad Nacional de Quilmes.

Balsa, J. (2009). Agro, capitalismo y explotaciones familiares: algunas reflexiones a partir de los casos del midwest norteamericano y la pampa argentina. En J.M. Cerdá y V. Guirérrez (Comp.s.). Trabajo agricola. Experiencias y resignificación de las identidades en el campo argentino, pp. 59-83. Buenos Aires, Argentina: CICCUS.

Banaji, J. (1997). Modernizing the Historiography of rural labour: an unwritten agenda. En: M. Bentley (Ed.). Companion to Historiography. Londres, Inglaterra: Rutledge.

Barsky, O. y Dávila, M. (2008). La rebelión del campo. Historia del conflicto agrario argentino. Buenos Aires, Argentina: Sudamericana.

Beaud, M. (2013). Historia del capitalismo. Barcelona, España: Ariel.

Bernstein, H. (2010). Class dynamics of agrarian change. Boulder, Estados Unidos: Kumarian Press.

Bocco, A. (1991). El empleo asalariado. En: O. Barsky (Ed.). El desarroIlo agropecuario pampeano, pp. 493-564. Buenos Aires, Argentina: Grupo Editor Latinoamericano.

Ciafardini, H. (1973). Capital, comercio y capitalismo: a propósito del llamado 'capitalismo comercial'. En Cuadernos de Pasado y Presente, (40), 111-134.

Ciafardini, H. (2014 [1984]). La Argentina en el mercado mundial contemporáneo. En G. Gresores, C. Spiguel y C. Mateu (Comps.). Reflexiones sobre Historia Social desde Nuestra América, pp. 211261. Buenos Aires, Argentina: Cienflores.

Felício, M. J. (2014). Paradigma da questãoagrária e paradigma do capitalismo agrário. En J. F. de Souza Campos Vinha, E. L. de Freitas Coca y B. Mançano Fernandes (Org.). Dataluta: questãoagrária e coletivo de pensamento, pp.17-38. São Paulo, Brasil: Outras Expressões . 
Flichman, G. (1978). Notas sobre el desarrollo agropecuario en la región pampeana argentina (o por qué Pergamino no es Iowa). Estudios CEDES , 1 (4/5), pp.5-52.

García Linera, A. (2008). La potencia plebeya. Buenos Aires, Argentina: CLACSO-Prometeo.

Harvey, D. (2003). El nuevo imperialismo. Madrid, España: Akal.

Hertz, T. (2016). Farm Labor. USDA Economic Research Service. Recuperado de https://www.ers.usda.gov/topics/farm-economy/farmlabor/

Hobsbawm, E. (2011 [1971]). Formaciones Económicas Precapitalistas. México, México: Siglo XXI.

Kautsky, K. (2002 [1899]). La cuestión agraria. México, México: Siglo XXI

Lenin, V.I. (1964 [1901]:417). El partido obrero y el campesinado. En V.I. Lenin. Obras Completas. Tomo IV, pp. 414-422. Buenos Aires, Argentina: Cártago.

Lenin, V.I. (1973 [1899]). El desarrollo del capitalismo en Rusia. Buenos Aires, Argentina: Cártago.

Lenin, V.I. (2016 [1916]). El imperialismo. Fase superior del capitalismo. Buenos Aires, Argentina: Cuadernos de Octubre.

Lódola, A. y Brigo, R. (2013). Contratistas de servicio agropecuarios, difusión tecnológica y redes agroalimentarias: una larga y productiva relación. En: G. Anlló, R. Bisang y M. Campi (Coords.). Claves para repensar el agro argentino, pp. 203-258. Buenos Aires, Argentina: EUDEBA.

Lombardo, P. y Tort, M.I. (2018). Contratismo de servicios de maquinara en el agro pampeano. Heterogeneidad de actores y vínculos. Buenos Aires, Argentina: Orientación Gráfica.

Luporini, C. et al. (1973). El concepto de 'Formación Económico-Social'. Cuadernos de Pasado y Presente, (39).

Marini, R.M. (2015). América Latina, dependencia y globalización. Antología. Buenos Aires, Argentina: CLACSO-Siglo XXI.

Marx, K. (1999 [1867]). El Capital. Tomo I. México, México: Fondo de Cultura Económica.

Marx, K. (2007 [1857/58]). Elementos fundamentales para la crítica de la Economía Política (Grundrisse) 1857/58. Madrid, España: Siglo XXI. 
Murmis, M. (1974). Tipos de capitalismo y estructura de clases. Buenos Aires, Argentina: La Rosa Blindada.

Patton, M. (2002). Purposeful sampling. En M. Patton. Qualitative research and evaluation methods. Thousand Oaks, Estados Unidos: Sage Publications.

Sartelli, E. (2010). En idéntica batalla. Razón y Revolución, (20), 133144.

Stedile, J. (2006). A questãoagrária no Brasil. Sao Paulo, Brasil: Expressão Popular.

Taylor, C. (1949). Rural life in Argentina. Baton Rouge, Estados Unidos: Lousiana State University Press.

Villulla, J. M. (2010). ¿Quién produce las cosechas récord? El 'boom’ sojero y el papel de los obreros rurales en la agricultura pampeana contemporánea. Realidad Económica (253).

Villulla, J.M. (2015) Las cosechas son ajenas. Historia de los trabajadores rurales detrás del agronegocio. Buenos Aires, Argentina: Cienflores.

Villulla, J.M. (2016). Intermediación laboral en la agricultura pampeana argentina: trabajadores asalariados y contratistas. Revista Eutopía, (9), 63-79.

Volkind, P. (2014). Entre la agricultura «de punta» y la «canción de otoño»: procesos de trabajo, medios de producción y relaciones sociales en los núcleos maiceros y trigueros bonaerenses, 1895-1920. Tesis Doctoral. Facultad de Filosofía y Letras de la Universidad de Buenos Aires. Mimeo.

Wallerstein, I. (2006). El capitalismo histórico. Madrid, España: Siglo XXI. Williams, R. (2001 [1973]). El campo y la ciudad. Buenos Aires, Argentina: Paidós. 